\title{
KAJIAN PENGARUH PSIKOLOGIS, SOSIAL DAN PROMOSI TERHADAP KEPUTUSAN PEMBELIAN DONAT BROWNIES (DONIES) SOLO DI SURAKARTA
}

\author{
Ika Ratna Pertiwi ${ }^{1}$, Supawi Pawenang ${ }^{2}$, Solichul Hadi A.B ${ }^{3}$ \\ Fakultas Ekonomi Program Studi Manajemen \\ Universitas Islam Batik Surakarta \\ J1. KH. Agus Salim No. 10 Surakarta 57147 \\ Email:2204ikar@gmail.com
}

\begin{abstract}
This study aims to determine the simultaneous and partial influence of psychological (X1), social (X2) and promotion (X3) on purchasing decisions of Solo Brownies (Donies) in Surakarta. In this study data were collected through observation, interviews, literature studies and questionnaires, and using SPSS version 23 assistance. This questionnaire was distributed to 150 respondents who were consumers of Solo Brownies Donuts. The analysis used in this study includes data instrument tests (validity and reliability tests), multiple linear regression analysis, classic assumption tests (normality test, multicollinearity test, heteroscedasticity test), and hypothesis testing ( $F$ test, $t$ test, coefficient of determination). The results of the analysis using regression can be seen that the Psychological (X1), social (X2) and promotion (X3) variables all have a positive effect on the decision to purchase a Solo brownie (Donies) in Surakarta. From the t test, the results obtained that psychological variables $(0,000)$, social $(0,000)$ and promotion (0,055). From the results of the data that has been analyzed so that it can be concluded that there is a positive and significant influence on psychological and social variables, then the promotion variable has an effect but is not significant on the purchasing decision of the Brownies Solo Donuts.
\end{abstract}

Keywords: psychological, social, promotion and purchasing decisions

\section{PENDAHULUAN}

Konsumen merupakan elemen penting dalam sebuah kegiatan pemasaran baik itu pemasaran produk barang maupun jasa. Keberadaan konsumen menjadi suatu hal tolak ukur bagi kesuksesan seorang pelaku usaha dalam memasarkan produk yang dimilikinya. Kepuasan dari konsumen adalah hal yang paling penting dalam manajemen pemasaran. Mengidentifikasi keinginan konsumen juga harus dilakukan sebelum menawarkan produk apa saja kepada konsumen (Yuzar, 2019). Donat Brownies atau sering disebut dengan (Donies Solo) ini pertama dibuka pada tahun 2014. Telah hadir dan berkembang menjadi produsen serta poiner seller donat yang melakukan inovasi dengan kombinasi Donat dan Brownies kualitas premium yang ikut mengembangkan diri untuk meramaikan dunia kuliner. Sejak didirikan sampai saat ini Donies Solo terus berkembang dalam jumlah gerai yang terus bertambah, konsep pelayanan, desain serta varian dari semua jenis makanan serta minuman (Sumber: Hasil Wawancara, pada tanggal 24 Oktober 2019). Pengguna media sosial sepanjang tahun 2016 sampai tahun 2017 meningkat sebanyak $51 \%$ artinya, lebih dari separuh masyarakat indonesia berfikir bahwa 
internet merupakan sumber informasi penting bagi mereka. Maka dari itu, pelaku bisnis berlomba - lomba membuat website yang unik agar dapat memasarkan usahanya secara luas di media sosial dan menarik calon pelanggan. Membuat website juga dapat memudahkan konsumen untuk melakukan pembelian, mengurangi biaya promosi yang biasanya membutuhkan biaya yang sangat besar (Danur, 2018). Keputusan pembelian (Weenas, 2013), konsumen bukanlah konsep yang baru dalam menentukan atau memilih suatu produk bukan terjadi begitu saja, banyak pertimbangan yang dilakukan para konsumen sebelum memutuskan untuk membeli suatu produk yang diinginkan.

\section{LANDASAN TEORI}

\section{Keputusan Pembelian}

Keputusan pembelian merupakan sikap konsumen untuk mencari infomasi dan mengambil kesimpulan berupa respon yang timbul tentang produk apa yang akan dibeli. Keputusan pembelian (Tjiptono, 2014, p. 21), sebuah proses dimana konsumen mengenal masalahnya, mencari informasi tentang produk atau merek yang akan dibeli serta mengevaluasi secara baik - baik dari alternatif tersebut hingga dapat informasi yang di butuhkan kemudian akan melakukan keputusan pembelian. Menurut Ardiana (2018) keputusan pembelian dipengaruhi oleh kualitas layanan.

\section{Perilaku Konsumen}

Dalam dunia pemasaran kita semua tidak akan bisa lepas dari pengarahan perilaku konsumen, seringkali kebutuhan konsumen ini tidak terpenuhi dan akan menunjukkan perilaku kecewa. Perilaku konsumen (Sopiah \& Sangadji, 2013, p. 8), merupakan suatu kegiatan dan proses psikologi yang mendorong tindakan saat sebelum melakukan pembelian, ketika membeli, menggunakan, menghabiskan produk serta jasa setelah melakukan hal - hal diatas atau kegiatan mengevaluasi. Perilaku pembelian konsumen atau karakteristik konsumen dipengaruhi oleh empat faktor Budaya, Sosial, Pribadi dan Psikologis, akan tetapi penulis mengambil dua faktor perilaku konsumen untuk di jadikan bahan penelitian.

\section{Faktor Psikologis}

Faktor Psikologis (Peter \& Olson, 2013), pemilihan pembelian seseorang dapat dipengaruhi oleh empat faktor yaitu :
a. Motivasi
b. Persepsi
c. Pembelajaran
d. Keyakinan dan sikap

\section{Faktor Sosial}

Faktor sosial (Keller \& Kotler, 2012, p. 135) seperti kelompok sosial, keluarga, serta peranan dan status sosial merupakan aspek eksternal yang mendorong keputusan pembelian.
a. Kelompok acuan
b. Keluarga
c. Peran dan Status 


\section{Promosi}

Promosi (Arman, 2015, p. 627), merupakan segala bentuk komunikasi yang digunakan untuk menginformasikan (inform), membujuk (persuade) atau mengingatkan kepada orang - orang tentang produk yang dihasilkan organisasi, individu maupun rumah tangga.

\section{METODELOGI PENELITIAN}

Penelitian ini merupakan penelitian analisis deskriptif yang menggunakan metode regresi berganda. Dalam penelitian ini hanya menggunakan empat variabel yaitu Psikologis, Sosial, Promosi dan Keputusan Pembelian. Peneliti menggunakan responden yang diteliti dalam penelitian ini berjumlah 150 konsumen yang sudah pernah membeli di Donat Brownies (Donies) Solo di Surakarta. Teknik pengambilan sampel pada penelitian ini dengan menggunakan non probability sampling. Metode non probability sampling merupakan teknik pengambilan sampel yang tidak memberikan kesempatan sama bagi setiap anggota populasi untuk dipilih menjadi sampel, menggunakan pendekatan accidental sampling.

\section{HASIL DAN PEMBAHASAN}

\section{Uji Asumsi Klasik}

a. Uji Normalitas

Uji normalitas data dalam sebuah penelitian mempunyai tujuan untuk menguji apakah dalam model regresi, variabel terikat dan variabel bebas keduanya mempunyai distribusi normal atau tidak. Model regresi yang baik adalah yang memiliki distribusi normal atau mendekati normal.

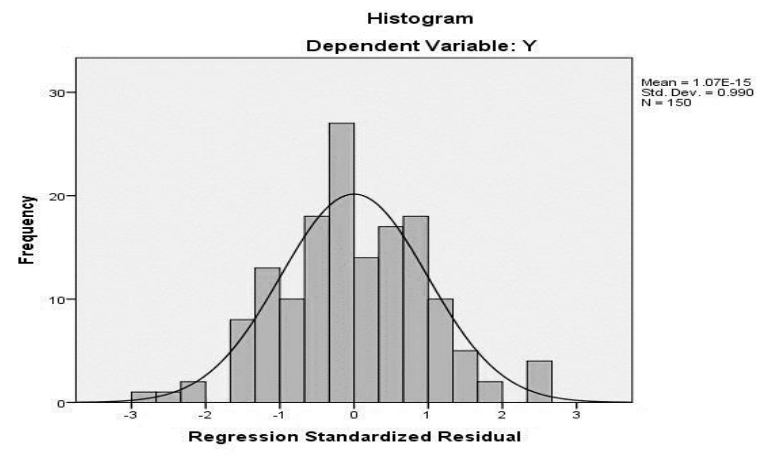

Gambar. 1 Histogram Uji Normalitas

Berdasarkan gambar grafik diatas dapat disimpulkan bahwa grafik histogram memberikan pola distribusi yang normal karena gambar menunjukan lengkungan cekung seperti lonceng.

\section{Uji Multikoliniearitas}

Uji multikolinearitas dalam sebuat penelitian bertujuan untuk menguji apakah ditemukan kolerasi antar variabel bebas. Uji multikoleniaritas dapat dilihat dari tolerance dan Variance Inflation Factor (VIF). Nilai yang umum digunakan untuk menunjukkan tidak adanya multikolinearitas adalah nilai tolerance $>0,1$ atau sama dengan niali VIF $<10$. 
Tabel 1 Uji Multikolinearitas

\begin{tabular}{|c|c|c|c|c|c|c|c|c|}
\hline \multirow[b]{2}{*}{ Hodel } & & \multicolumn{2}{|c|}{ Unstandardized Coefficients } & \multirow{2}{*}{$\begin{array}{c}\text { Standardized } \\
\text { Coefficients } \\
\text { Beta }\end{array}$} & \multirow[b]{2}{*}{1} & \multirow[b]{2}{*}{ sig. } & \multicolumn{2}{|c|}{ Collinearity Statistics } \\
\hline & & $\theta$ & Sto Eror & & & & Tolerance & VF \\
\hline 1 & (Constant) & .910 & .951 & & .957 & 340 & & \\
\hline & $x 1$ & .495 & .083 & .459 & 5.946 & .000 & .149 & 6728 \\
\hline & $x_{2}$ & .449 & .091 & .394 & 4.915 & .000 & .198 & 7.240 \\
\hline & $x_{3}$ & .126 & .065 & .112 & 1.933 & .055 & .263 & 3.800 \\
\hline
\end{tabular}

Sumber : Data primer diolah 2019

Berdasarkan data tabel diatas, dapat dilihat bahwa nilai tolerance $\mathrm{X} 1$ sebesar $0,149, \mathrm{X} 2$ sebesar 0,138, dan X3 sebesar 0,263 dimana nilai tolerance tersebut lebih besar dari 0,1 dan nilai VIF dari X1 sebesar 6,6728, X2 sebesar 7,240 dan X3 sebesar 3,800 dimana nilai VIF kurang dari 10, sehinga dapat disimpulkan bahwa dalam penelitian ini tidak ada multikolinearitas antar variabel independent dalam model regresi.

\section{c. Uji Heterokedastisitas}

Jika titik data menyebar diatas dan dibawah atau disekitar angka 0 pada sumbu $\mathrm{Y}$ tanpa membentuk pola tertentu, maka data tersebut dikatakan tidak terjadi heteroskedastisitas. Hasil uji heteroskedastisitas pada penelitian ini dapat dilihat pada grafik scatterplot berikut :

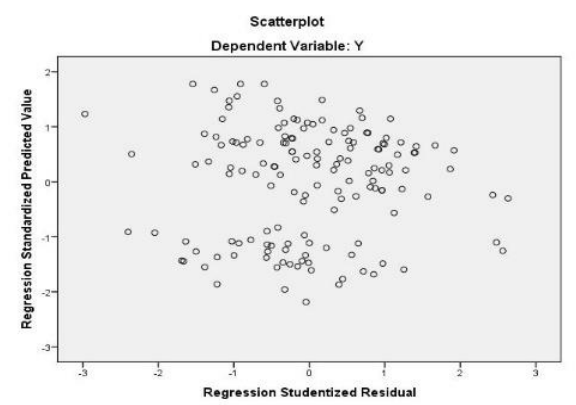

Gambar 1 Hasil Uji Heteroskedastisitas

Scatterplot diatas menunjukan titik menyebar secara acak diatas dan dibawah angka 0 pada sumbu Y. maka dapat disimpulkan tidak terjadi heteroskedastisitas pada model regresi penelitian ini dan layak digunakan untuk variabel psikologis, sosial dan promosi terhadap keputusan pembelian.

\section{Analisis Data}

a. Regresi Linear Berganda

Berdasarkan hasil pengolahan data model regresi dengan program SPSS versi 23 dijelaskan dalam hasil pengolahan data sebagai berikut : 
Tabel 2 Hasil Regresi Linear Berganda

Coefficients $^{\mathrm{a}}$

\begin{tabular}{|c|c|c|c|c|c|c|}
\hline \multirow[b]{2}{*}{ Model } & & \multicolumn{2}{|c|}{ Unstandardized Coefficients } & \multirow{2}{*}{$\begin{array}{c}\begin{array}{c}\text { Standardized } \\
\text { Coefficients }\end{array} \\
\text { Beta }\end{array}$} & \multirow[b]{2}{*}{$t$} & \multirow[b]{2}{*}{ Sig. } \\
\hline & & $B$ & Std. Error & & & \\
\hline 1 & (Constant) & .910 & .951 & & -.957 & .340 \\
\hline & $X 1$ & .495 & .083 & .459 & 5.946 & .000 \\
\hline & $X 2$ & .449 & .091 & .394 & 4.915 & .000 \\
\hline & X3 & .126 & .065 & .112 & 1.933 & .055 \\
\hline
\end{tabular}

Sumber : Data primer diolah tahun 2019

Berdasarkan tabel diatas dapat diketahui nilai koefisien regresi, maka dapat disusun analisis regresi sebagai berikut.

$$
\begin{aligned}
& Y=a+b 1 X 1+b 2 X 2+b 3 X 3+e \\
& Y=(-0,910)+0,495 X 1+0,449 X 2+0,126 X 3+e
\end{aligned}
$$

Hasil analisis dapat di interpretasi dari persamaan tersebut adalah :

1) Nilai konstanta (a) $=-0,910$, artinya jika variabel faktor psikologis, sosial dan promosi nilainya 0 , maka pengambilan keputusan nilainya $-0,910$.

2) Nilai koefisien regresi variabel psikologis (b1) = Setiap penambahan variabel faktor sosial sebesar satu satuan, maka akan meningkatkan pengambilan keputusan pembelian sebesar 0,495 satuan dengan asumsi variabel sosial dan promosi dianggap konstan.

3) Nilai koefisien regresi variabel faktor sosial (b2) = Setiap penambahan variabel faktor psikologis sebesar satu satuan, maka akan meningkatkan pengambilan keputusan pembelian sebesar 0.449 satuan dengan asumsi variabel psikologis dan promosi dianggap konstan.

4) Nilai koefisien regresi variabel promosi (b3) = Setiap penambahan variabel promosi sebesar satu satuan, maka akan meningkatkan pengambilan keputusan pembelian sebesar 0.126 satuan dengan asumsi variabel sosial dan psikologis dianggap konstan.

b. Hasil Koefisien Determinasi R2 Hasil dari koefisien determinasi R2 dapat dilihat pada output analisis data sebagai berikut :

\begin{tabular}{|c|c|c|c|c|c|}
\hline \multicolumn{6}{|c|}{ Model Summary' } \\
\hline Model & $R$ & R Square & $\begin{array}{l}\text { Adjustedr R } \\
\text { Square }\end{array}$ & $\begin{array}{l}\text { Stt. Error of } \\
\text { the Estimate }\end{array}$ & $\begin{array}{l}\text { Durbin- } \\
\text { Watson }\end{array}$ \\
\hline 1 & $.933^{\mathrm{d}}$ & .871 & .868 & 3.21726 & 2.062 \\
\hline
\end{tabular}

Tabel 2 Hasil Uji Koefisien Determinasi 
Berdasarkan hasil analisis tersebut diperoleh nilai Adjusted R Square (R2) sebesar 0,868 atau $86,8 \%$. Artinya variabel sosial, psikologis dan promosi memiliki pengaruh sebesar $86,8 \%$ terhadap variabel keputusan pembelian Donies Solo di Surakarta. Sedangkan sisanya sebesar $13,2 \%(100 \%-86,8 \%)$ dipengaruhi oleh variabel lain seperti harga, lokasi dan lain - lain.

\section{PEMBAHASAN}

Berdasarkan hasil uji $\mathrm{F}$ bahwa nilai Fhitung sebesar 327,345 dan signifikansi sebesar 0,000 sehingga Fhitung > Ftabel $(327,345>2,67)$ dengan tingkat signifikansi $(0,000<0,05)$. Artinya variabel psikologis, sosial dan promosi secara simultan berpengaruh terhadap keputusan pembelian. Keputusan pembelian Donat Brownies Solo di Surakarta dipengaruhi oleh psikologis, sosial dan promosi sebesar $86,8 \%$ dimana hasil analisis regresi linear berganda menunjukan bahwa psikologis (X1) ada pengaruh yang paling dominan terhadap keputusan pembelian (Y) karena koefisien regresinya paling besar yaitu 0,495.

\section{KESIMPULAN}

Berdasarkan hasil penelitian serta pembahasan mengenai faktor psikologis, sosial dan promosi terhadap keputusan pembelian produk Donies Solo di Surakarta. Hasil pengujian dalam penelitian ini dari uji $\mathrm{F}$ variabel faktor psikologis, sosial, dan promosi menunjukan secara simultan atau bersama - sama berpengaruh positif terhadap keputusan pembelian produk Donies Solo di Surakarta. Hasil perhitungan dari Fhitung sebesar 361,063 dan signifikansi sebesar 0,000 $<0,05$. Keputusan pembelian dipengaruhi oleh faktor psikologis, sosial dan promosi sebesar $87,9 \%$. Variabel yang paling berpengaruh atau paling dominan dalam keputusan pembelian (Y) adalah variabel psikologis karena koefisien regresinya paling besar yaitu 0,481 .

\section{Implikasi}

Hasil dari penelitian ini menggambarkan adanya pengaruh antara variabel psikologis, sosial dan promosi terhadap keputusan pembelian Donies Solo di Surakarta, dimana variabel psikologis dan sosial berpengaruh positif serta signifikan terhadap keputusan pembelian Donies Solo, tetapi ada satu variabel yang berpengaruh positif tapi tidak signifikan yaitu variabel promosi. Dari hasil kesimpulan penelitian ini terbukti bahwa variabel psikologis memiliki pengaruh yang paling dominan terhadap keputusan pembelian Donat Brownies Solo dibandingkan dengan variabel lain seperti faktor sosial dan promosi. Secara lebih spesifik konsumen lebih suka membeli di Donies Solo, karena topping donat yang menarik, memiliki rasa yang enak dan percaya akan bahan yang digunakan berkualitas serta aman untuk di konsumsi, sehingga para konsumen memutuskan akan membeli ulang di Donies Solo. Akan tetapi ada juga beberapa konsumen lebih merasa senang membeli jenis makanan yang mahal, padahal produk yang mereka konsumsi sama saja yang dipasarkan oleh para pelaku usaha yang lainnya.

\section{Saran}

Berdasarkan hasil penelitian, pembahasan serta kesimpulan yang diperoleh, maka saran yang dapat diberikan sebagai berikut :

Dari penelitian ini diharapkan Donies Solo menjadi lebih mengetahui faktor keputusan konsumen itu dari apa, hasil penelitian ini menunjukkan variabel yang paling terendah adalah variabel promosi. Maka dari itu diharapkan mananger Donies Solo agar dapat mempertahankan loyalitas konsumen, Donies Solo harus menciptakan strategi promosi yang lebih baik lagi dan dapat menambah jenis promo yang lebih banyak lagi agar dapat menarik konsumen untuk tetap 
membeli di Donies Solo dan tetap mempertahankan hingga dapat meningkatkan jumlah pendapatan dari Donies Solo.

\section{DAFTAR PUSTAKA}

Ardiana, T. E. (2018). The Effect Of The Perception Of Service Quality On The Decision Of Purchase In Dawet Jabung Traders In Ponorogo. International Journal of Economics, Business and Accounting Research (IJEBAR), 2(04).

Arman, Andri. (2015). Analisis Bauran Promosi Terhadap Keputusan Konsumen Membeli Sepeda Motor Merek Yamaha Pada CV. Sinar Utama Cabang Antasari di Samarinda. eJournal Ilmu Administrasi Bisnis.

Danur. (2018). 25 Alasan Kenapa Pelaku Bisnis Perlu Membuat Website. Retrieved from https://indonesiago.digital/25-alasan-kenapa-pelaku-bisnis-perlu membuat-website/. (Diakses tanggal 17 November 2019. Pukul 18.45 WIB).

Keller dan Kotler. (2012). Manajemen Pemasaran. Edisi 12. Jakarta: Erlangga.

Peter, Paul J., dan C. Jerry Olson. (2013). Perilaku Konsumen dan Strategi Pemasaran (Jilid 1). Jakarta.

Sopiah dan Sangadji, E.M. (2013). Prilaku Konsumen: Pendekatan Praktis Disertai: Himpunan Jurnal Penelitian. Yogyakarta : Andi Offset.

Tjiptono, Fandy. (2014). Pemasaran Jasa - Prinsip, Penerapan dan Penelitian. Yogyakarta: Andi Offset.

Weenas, Jackson. (2013). Kualitas Produk, Harga, Promosi Dan Kualitas Pelayanan Pengaruhnya Terhadap Keputusan Pembelian Spring Bed Comforta. Jurnal Riset Ekonomi, Manajemen, Bisnis Dan Akuntansi, 1(4), 607-618.

Yuzar, Iqbal Mohammad. (2019). Perlunya Manajemen Pemasaran dalam Berbisnis. Retrieved from https://jojonomic.com/blog/manajemen-pemasaran/. (Diakses tanggal 22 November 2019. Pukul 20.30 WIB). 